\title{
Arbor
}

\section{Teatro clásico e iniciativa pública}

\section{Luciano García Lorenzo}

Arbor CLXXVII, 699-700 (Marzo-Abril 2004), 545-560 pp.

El desarrollo de la puesta en escena del teatro clásico español en los últimos veinticinco años se ha debido a diferentes causas y de diverso carácter. En este trabajo se estudia una de ellas: la labor de la iniciativa pública estatal y, especialmente, con dos magníficas realidades: el Festival Internacional de Teatro Clásico de Almagro y la Compañía Nacional de Teatro Clásico.

El acercamiento a la presencia de los clásicos en los escenarios españoles se ha visto enriquecido en los últimos años con no pocos trabajos, aparecidos en publicaciones de muy diverso carácter (vid. Bibliografía). Este interés tiene, en buena parte, como causa el mayor número de puestas en escena de Lope, Calderón, Shakespeare, etc., evidentes, sobre todo, desde los años ochenta del pasado siglo. Naturalmente, muchos de estos montajes han sido realizados por compañías de carácter privado, algunas de ellas de importancia definitiva para entender cualquier aspecto relacionado con nuestros autores de los siglos XVI y XVII. En el presente trabajo, sin embargo, vamos a prestar atención al interés que por nuestros clásicos se ha hecho desde la iniciativa pública $\mathrm{y}$, fundamentalmente, de carácter nacional, dejando, para otro momento, la importancia que han tenido instituciones de carácter no nacional y que, en algunos casos, han aportado espectáculos que deben ser situados en primera línea de los mejores que han llegado a los escenarios. Nos referimos, por ejemplo, al Centro Andaluz de Teatro, al Centro Dramático de Aragón o al recién creado en Castilla y León y que se ha estrenado en el 
año 2003 con el montaje, muy oportuno, de El Caballero de Olmedo de Lope de Vega.

Pero, desde el punto de vista nacional, dos han sido y son las experiencias más relevantes y que, con lo citado anteriormente, podrían ser las bases del fenómeno que estudiamos. Nos estamos refiriendo al Festival Internacional de Teatro Clásico de Almagro (FITCA) y a la Compañía Nacional de Teatro Clásico (CNTC).

\section{Festival de Almagro}

El Festival de Almagro tiene sus orígenes en las Jornadas de Teatro Clásico, que se celebraron en esa ciudad en el mes de septiembre de 1978. Las Jornadas de Estudio, en las que participaron profesores, críticos, directores de escena, actores, etc., fueron el eje fundamental de esta convocatoria y estuvieron acompañados por tres espectáculos: Medora de Lope de Rueda (puesta en escena de la Real Escuela de Arte Dramático de Madrid), El despertar a quien duerme, de Lope de Vega, con dirección de José Luis Alonso Mañes, y La estrella de Sevilla, también de Lope y bajo la dirección de Alberto González Vergel. El Festival, que en el 2004 ha cumplido ya veintisiete ediciones, ha ofrecido desde 1978 decenas de espectáculos y por sus diferentes espacios han pasado numerosas compañías, directores, escenógrafos, etc., y centenares de actores. Citar los nombres de estos profesionales sería hacer la historia del teatro español contemporáneo, sobre todo, claro está, en lo que se refiere a los clásicos, pues en Almagro han trabajado desde Amparo Rivelles y María Jesús Valdés hasta Ana Belén o Adriana Ozores, desde Jesús Puente y José Luis Pellicena hasta Manuel Galiana o Carlos Hipólito, desde José Luis Alonso Mañes y Adolfo Marsillach hasta Miguel Narros y José Carlos Plaza, desde Emilio Burgos y Francisco Nieva hasta Fabià Puigserver y Carlos Cytrynowski...

Pero el Festival de Almagro lleva en su denominación la marca de «internacional» $y$, efectivamente, desde principios de los ochenta son muy numerosas las compañías extranjeras que han presentado sus espectáculos en la ciudad manchega. Inglaterra, especialmente, y con obras, como es natural, de Shakespeare; Francia, Italia, Portugal, Luxemburgo, Bulgaria, Polonia, Checoslovaquia, etc., entre los países europeos; México, Estados Unidos, Venezuela, Colombia, Puerto Rico, etc., entre los americanos; y otros lugares tan lejanos como Bali, Sudáfrica o Japón son algunos de los países representados en el Festival. En el recuerdo de los 
espectadores están presentes todavía representaciones inolvidables, como La vida es sueño montada en la Iglesia de San Agustín por una agrupación búlgara, el ejercicio de maestría teatral llevado a cabo por la New Shakespeare Company, los deliciosos espectáculos del TAG de Venecia, los entrañables del Repertorio Español de New York o la presencia de los hermosísimos que con la tradición teatral española o italiana ha jugado Mauricio Scaparro o la sabiduría en escena de Declan Donellan...

El Festival de Almagro tiene, naturalmente, como función fundamental esa muestra de espectáculos de Teatro Clásico y para ello utiliza una serie de espacios a los que nos referiremos a continuación; sin embargo, y desde hace algunos años, Almagro ofrece también durante el mes de julio teatro en espacios abiertos, fundamentalmente los fines de semana y también, desde 1997 y de una manera regular, se ponen en escena diferentes montajes de Teatro infantil. Los espacios para el Teatro de Calle han sido muy diversos y para el Infantil fue primero la Plaza de Santo Domingo y en los últimos años el Palacio de los Fúcares y el Patio del Museo del Teatro. Tanto en un caso como en otro se procura que los espectáculos tengan como referencia directa o indirecta la tradición clásica.

En fin, mencionaremos en este capítulo de exhibiciones las que desde hace dos años se llevan a cabo los fines de semana y que, bajo el título «Trasnochando», tienen lugar al finalizar las funciones en los diferentes espacios. Se trata de espectáculos de carácter dramático o musical, siempre con la literatura clásica o tradicional como referencia, y buscando la presencia de los espectadores en espacios más informales y como cierre, camino da la madrugada, de unas jornadas que se procuran estén llenas de actividades. En esa línea de mayor participación del público también cabría recordar los «Encuentros»: reunión los sábados o domingos a última hora de la mañana de los espectadores con directores, actores, etc., con el fin de dialogar en torno a los espectáculos presenciados o sobre la actividad teatral en general.

\section{Espacios Teatrales}

El Festival de Almagro cuenta desde hace algunos àños con cinco espacios estables y algunos otros utilizados intermitentemente y dependiendo de la programación ofrecida. El más emblemático de estos espacios es, naturalmente, el Corral de Comedias, declarado monumento 
nacional, lugar único en España y también en Europa, que permanece desde la época de nuestro teatro barroco y del teatro isabelino. La construcción del Corral o Posada de Comedias data de 1628 y en él se ofrecieron espectáculos hasta principios del XVIII. Fue recuperado en los años cincuenta del siglo pasado, dándose en su recinto desde entonces representaciones, pero siendo, fundamentalmente, el centro de atención en el mes de julio, cuando se celebra el Festival. En el Corral las escenografías son mínimas y el aprovechamiento de este espacio por parte de las Compañías viene, sobre todo, a través de la palabra. Por otra parte, el Corral alberga habitualmente los no pocos espectáculos que han tenido a la música como protagonista: por Almagro han pasado óperas barrocas o artista de la talla de Jordi Savall o Raimon, y todos ellos han colaborado a que la magia del Corral se vea acentuada y no sólo a través del recitado de la palabra.

Un segundo espacio, mucho más amplio en su aforo que el anterior, esl el denominado Claustro de los Dominicos. Se trata, efectivamente, del magnífico Claustro del Convento de la Asunción Calatrava, el mejor testimonio que permanece en Almagro de esta Orden. Finalizó su construcción en 1543 y es utilizado por el Festival desde 1980. Es un espacio amplio, hermosísimo, con sesenta columnas de mármol de Carrara, y bases y capiteles de estilo dórico y jónico. Una majestuosa escalera de piedra conduce al segundo piso del Claustro, donde se sitúan los servicios técnicos durante el Festival, aunque buena parte de este Claustro alto también ha acogido parte de algunos montajes que han pasado por este envidiable escenario.

El tercero de los lugares que acoge permanentemente representaciones es el Teatro Municipal, el único, por otra parte, cubierto. Data su inauguración de 1865 y está situado en la calle de San Agustín, no lejos de la Plaza Mayor, del Corral y del Hospital de San Juan. Es un local pequeño, coquetón, "una bombonera", como también se define al Coliseo Carlos III del Escorial, en el cual está inspirada su construcción. El Municipal ha pasado desde épocas de esplendor hasta la desidia y el abandono. En la década de los ochenta, diversas instituciones se decidieron, por fin, a salvar este precioso local encargando su rehabilitación al arquitecto Miguel Fisac y abriendo de nuevo en 1989. Hoy, el Teatro Municipal es pieza fundamental para el Festival, utilizándose con mucha frecuencia también a lo largo del año, precisamente por ser el único lugar cubierto y, por lo tanto, accesible durante cualquier época del año.

Otro de los espacios que se ha incorporado a la muestra almagreña ha sido el Hospital de San Juan, fundado por la Orden de Calatrava en el siglo XVII, situado frente a la Iglesia de San Blas y no lejos de esa otra 
joya que es la de San Agustín. De reciente construcción (fue inaugurado en 1994), San Juan es el marco habitual para las representaciones de la Compañía Nacional de Teatro Clásico, tiene capacidad para cerca de 700 espectadores y el cielo también como techo. San Juan es un espacio polivalente, ya que, al lado del auditorio y de su grandioso escenario, hay. también una Sala de Exposiciones y allí se encuentran parte de las oficinas del Festival: las de Administración y las de la Dirección Técnica. En esa sala de exposiciones, como así mismo en otros lugares emblemáticos de la ciudad, se montan todos los años exposiciones relacionadas con la escena y siempre teniendo como organizador, directa o indirectamente, al Museo Nacional del Teatro.

El último espacio permanente incorporado al Festival es el Patio del Palacio de los Fúcares, hoy destinado a Universidad Popular. Este edificio data del siglo XVI y fue, primitivamente, un almacén que albergaba mercurio y grano. El Patio, de hermosa factura renacentista, es de planta cuadrada con dos galerías que tienen arcos de ladrillo apoyados en columnas de piedra. Es utilizado para espectáculos de pequeño y mediano formato, habiéndose repetido durante los últimos años en él, fundamentalmente, los montajes de compañías extranjeras y los dè teatro infantil.

Recordemos, para finalizar, otros espacios como la excepcional Plaza Mayor, la Iglesia de San Agustín (y en ella teatro y exposiciones), la Iglesia de San Blas, el antiguo Casino, el Callejón del Villar... Y el Museo Nacional del Teatro, institución sin la cual pocas cosas se explicarían de las que exponemos en este trabajo.

\section{Unas señas de identidad}

El Festival de Almagro, después de todo lo dicho hasta aquí, manifiesta claramente ese carácter excepcional entre los acontecimientos teatrales que se ofrecen en España, pudiendo considerarse como el motor fundamental, junto a la Compañía Nacional de Teatro Clásico y a los esfuerzos de ciertas compañías privadas, de la relativa buena salud que parecen gozar nuestros clásicos en los escenarios. El Festival, con una continuidad digna de reconocimiento, ha mantenido una línea ascendente que se manifiesta tanto en la calidad de los espectáculos como en la asistencia de público, y quizá todo ello debido a una coherencia y unas señas de identidad a las que nos hemos referido en otras ocasiones y que podríamos resumir así:

- Utilización de un espacio inigualable y plenamente identificador de un tipo de teatro determinado, como es el Corral de Comedias, si- 
tuado, por otra parte, en un lugar estratégico: la Plaza Mayor de Almagro, centro de la actividad teatral durante el mes de julio que se lleva a cabo en lugares concretos y también en calles y plazas que rodean a la que identifica artísticamente, y de una manera muy original, a la ciudad calatraveña. Representar obras clásicas en el Corral de Comedias es un honor (y un reto) para todas las compañías que se acercan al montaje de los clásicos tanto en España como en otros países.

- Posibilidad de contrastar estilos diferentes al poder verse, en casi un mes de Teatro Clásico, un centenar de representaciones, puestas en escena diversas desde contextos culturales, lingüísticos y teatrales muy diferentes y con autores que no son solo los españoles de nuestros siglos XVI y XVII, sino también los dramaturgos considerados clásicos en otros países. Por Almagro han pasado autores como Lope, Calderón, Shakespeare o Molière, pero también escritores de teatro considerados de menor importancia de la misma manera que al lado de Hamlet o Fuente Ovejuna se han podido disfrutar montajes de entremeses, comedias de improviso o piezas breves en otras lenguas.

- Lugar de encuentro para profesionales del teatro en el campo de la representación y estudiosos desde la vertiente académica o de la crítica teatral. No olvidemos, que como ya hemos dicho, el Festival nación por unas Jornadas de estudio y que, desde entonces, una de las actividades fundamentales del Festival es la reunión de especialistas de esos dos mundos, principalmente en las Jornadas, pero también en los no pocos Seminarios que se han llevado a cabo en el Festival. Importantísimo testimonio de todo ello son las Actas de esas reuniones, que se vienen publicando, con escasas excepciones desde 1978 y desde hace bastantes años por la Universidad de Castilla La Mancha.

- Lugar de encuentro y también de formación para numerosos estudiantes y futuros profesionales del teatro. Efectivamente, durante el mes de julio se llevan a cabo diversos encuentros y talleres sobre aspectos de muy diferente carácter y dedicados a jóvenes escenógrafos, actores, directores, etc. Digna de recuerdo es la labor de prácticas que en Almagro han llevado a cabo los estudiantes de la Escuela de Tecnología del Espectáculo y también las que, desde otras instancias formativas y profesionales, tienen Almagro como centro. De algunos de esos talleres y encuentros el Festival ha publicado diferentes volúmenes en los seis últimos años, como los de- 
dicados a la historia del propio Festival, a Calderón, a la labor de autoras y actrices; etc. El último de estos libros ha estado dedicado a Miguel Narros con motivo de serle concedido el Premio del Festival de Almagro 2002 (el primero, en 2001, lo fue a la Comédie Française, el de 2003 a Francisco Ruiz Ramón y el de 2004 a la Froyal Shakespeare Company). Otros premios que se otorgan son los denominados «Clásicos» y «Ágora», éstos últimos con jurado compuesto por representantes de los medios de comunicación destacados en Almagro durante el Festival.

En fin, más de un cuarto de siglo de Festival ha supuesto para Almagro y para el Teatro Clásico uno de los testimonios más importantes de la cultura contemporánea española, al mismo tiempo que un ejemplo de continuidad y coordinación entre instituciones de carácter nacional, regional y local. Efectivamente, las ayudas económicas que hacen posible esta Muestra provienen a través de un Patronato, en el que están representados el Ministerio de Cultura, la Junta de Comunidades de Castilla La Mancha, la Diputación de Ciudad Real y el Ayuntamiento de Almagro, responsabilizándose de las Jornadas la Universidad de Castilla La Mancha, también presente en el Patronato desde hace algunos años. A todo esto debemos añadir la incorporación, desde 1997, de recursos generados por el Festival de la iniciativa privada, aunque sea ésta una asignatura, que, como en la mayor parte de las actividades artísticas, se vea muy limitada en las cantidades obtenidas y nunca en proporción con los esfuerzos que a ello se dedica.

\section{Compañía Nacional de Teatro Clásico}

La Compañía Nacional de Teatro Clásico es una unidad de producción del Instituto Nacional de las Artes Escénicas y de la Música del Ministerio de Cultura, creada por la Orden ministerial del 14 de enero de 1986. La CNTC fue fundada con la misión de recuperar, conservar y poner en escena los textos teatrales clásicos, fundamentalmente españoles, aunque también de otras lenguas y culturas. Por otra parte, tiene además como misión la investigación y divulgación de este teatro y, naturalmente, la formación de profesionales especializados en el teatro clásico. La CNTC ha intentado, efectivamente, durante los dieciocho últimos años recuperar una tradición que durante las décadas anteriores había permanecido de una manera muy irregular y por la presentación intermitente de espectáculos de muy desigual bondad artística. Estas puestas en 
escena se debieron más al voluntarismo de diferentes profesionales del teatro que a una política teatral a medio o largo plazo, prácticamente inexistente.

La CNTC tiene una estructura muy parecida a la de otras unidades de producción en España o de otros grandes teatros europeos. Mantiene un equipo de dirección permanente, compuesto por un Director (hasta ahora lo han sido Adolfo Marsillach, Rafael Pérez Sierra, Andrés Amorós y José Luis Alonso de Santos) y departamentos de producción, técnico, de gerencia y promoción y prensa. La Compañía mantiene una plantilla también permanente de técnicos, aunque cada espectáculo exige la contratación de un director de escena, un escenógrafo, un iluminador...

La sede habitual de la CNTC es el Teatro de la Comedia de Madrid, aunque, debido a las obras que en él se están efectuando desde hace algunos años, las representaciones se llevan a cabo en el Teatro Pavón. La Compañía pone en escena, habitualmente, dos obras por año, que se mantienen a lo largo de una temporada teatral en régimen rotativo. En su sede del Teatro de la Comedia también se representan obras clásicas montadas por otras compañías, como ha sucedido con el Teatre Lliure, Moma Teatre, Compañía de Miguel Narros... La CNTC lleva también sus montajes a otros lugares de España y a espacios fuera de nuestras fronteras. Hasta ahora han sido numerosas las ciudades españolas visitadas y la Compañía ha ofrecido sus espectáculos en Europa (Alemania, Inglaterra), y en Iberoamérica (México, Argentina, Colombia, Chile...).

Hasta el verano de 2004, la CNTC ha puesto en escena más de 40 espectáculos, fundamentalmente de Lope de Vega y de Calderón de la Barca; en menor medida, también, de Tirso de Molina, Agustín Moreto, Fernando de Rojas, Juan Ruiz de Alarcón, Miguel de Cervantes, Guillem de Castro, Rojas Zorrilla, José Zorrilla, Molière... A esta nómina habría que añadir la Fiesta Barroca, realizada sobre textos de Calderón y Quiñones de Benavente. La CNTC ha montado hasta ahora buena parte de los textos más importantes del teatro clásico español ( $E l$ médico de su honra, La Celestina, El Burlador de Sevilla, El alcalde de Zalamea, El caballero de Olmedo, Fuente Ovejuna, La vida es sueño, Peribáñez y el Comendador de Ocaña...), pero ha complementado estas puestas en escena con obras consideradas de menor reconocimiento como $\mathrm{El}$ vergonzoso en palacio, La dama duende, Don Gil de las calzas verdes, La venganza de Tamar, La celosa de sí misma, entre otras. Por otra parte, la programación de la Compañía ha alternado la presentación de textos de carácter trágico o dramático con comedias, es decir, con obras con la comicidad como fin fundamental de esos textos. En cuanto a piezas de 
autores extranjeros, la Compañía ha puesto en escena El misántropo y Don Juan de Molière.

La CNTC produce sus propios espectáculos, pero también ha trabajado en colaboración con otras instituciones. Hasta el momento eso es lo que ha sucedido con el Teatro General San Martín de Buenos Aires (El burlador de Sevilla de Tirso de Molina), con los Teatros de la Generalitat Valenciana (Los malcasados de Valencia de Guillem de Castro), con el Centro de Producción teatral de Castilla y León (El Caballero de Olmedo, de Lope)... Un montaje especial fue el de la Fiesta Barroca, llevado a cabo con patrocinio exterior, durante el año 1992 y en un espacio inhabitual como la Plaza Mayor de Madrid.

Buena parte de las puestas en escena de la CNTC fueron realizadas por Adolfo Marsillach, mientras fue director de la Compañía. Sin embargo, no han sido pocas las obras montadas por otros directores. Hasta hoy han trabajado con textos de autores diversos Josefina Molina, Miguel Narros, José Luis Alonso, Gerardo Malla, Pilar Miró, José Luis Castro, Sergi Belbel, Ariel García Valdés, José Carlos Plaza, Denis Rafter, Joan Font, Calixto Bieito, Jean Pierre Miquel, Helena Pimenta, Eduardo Vasco, Luis Olmos, etc. También la escenografía ha sido responsabilidad de distintos profesionales (Montse Amenós, Andrea D’Odorico, Mario Bernedo, Julio Galán, Gustavo Torner, Pedro Moreno, Joan J. Guillén, José Hernández...), pero muchos montajes fueron realizados por Carlos Cytrynowski, colaborador habitual de Adolfo Marsillach, y primero director técnico y más tarde director adjunto de la CNTC. En fin, una preocupación de la Compañía ha sido la de complementar los espectáculos con música pertinente y rigurosa en cuanto al contexto histórico de la época se refiere; de ahí, que se hayan creado partituras por Carmelo Bernaola, Tomás Marco, Pedro Estevan, José Nieto, Claudio Prieto, etc.

Uno de los aspectos más controvertidos desde siempre en la representación de los clásicos ha sido el de las adaptaciones de los textos. La CNTC ha contado en no pocas ocasiones para realizar esta labor con escritores, fundamentalmente poetas, que garantizaran la calidad de los cambios y alteraciones necesariamente a efectuar en algunas ocasiones. Junto a los directores, máximos responsables de todos los aspectos del montaje de las obras, han trabajado como adaptadores Juan German Schroeder, Rafael Pérez Sierra, Gonzalo Torrente Ballester, Francisco Rico, Claudio Rodríguez, Francisco Brines, Francisco Brines, Francisco Nieva, Luis Alberto de Cuenca, José Caballero Bonald, Carlos Bousoño, Joan Oleza, José Hierro, Juan Mayorga... 
Aunque la misión fundamental de una compañía de teatro es, claro está, hacer espectáculos, la CNTC ha pretendido también cubrir una serie de actividades que complementan y favorecen la difusión y mejor entendimiento de los montajes de sus obras. La CNTC publicó, desde 1987, un Boletín fundamentalmente de carácter informativo, y que llegó a editar 34 números; también publica desde hace varios años sus Cuadernos de Teatro Clásico, fundados por quien esto firma y dedicados a temas monográficos y carentes de una bibliografía adecuada, con los cuales ha tendido un puente entre el mundo de la escena y el de la investigación universitaria. Por otra parte, edita todas las obras que estrena, versiones que van acompañadas de fotografías de diversos momentos del montaje. Este apartado de publicaciones se completa con unos materiales que, reunidos bajo el título Cuaderno pedagógico, van dirigidos a estudiantes de Enseñanza Secundaria con el propósito de complementar su asistencia a los espectáculos de la Compañía. En fin, la CNTC, a través de actores, su asesor literario, etc., visitó regularmente centros de enseñanza y también, en colaboración con «Anaya Educación», convocó durante algunos años un concurso de redacción sobre «El teatro clásico en escena», que está dirigido precisamente a esos estudiantes de Segunda enseñanza. Recordemos, también en esta línea, la presencia de la Compañía, por medio de algunos de sus componentes, en coloquios, conferencias, etc. Así ha sucedido en diversos lugares de España, Inglaterra, Cuba, Argentina, EEUU, Francia, Italia...

Después de 18 años, la CNTC ha logrado, y así es reconocida, una presencia activa y respetada en el mundo teatral español. Sus montajes han recibido, en general, una aceptación positiva por parte de público y crítica, aunque en algunas ocasiones el desacuerdo por parte de algunos críticos se ha manifestado incluso con mucha dureza. Lo que sí podemos afirmar, pues las cifras así lo indican, es que los espectáculos de la CNTC han sido vistos por decenas de miles de espectadores, y que el índice de ocupación de los lugares en que representa llega con mucha frecuencia al cien por cien. La frase «ir al clásico» se ha convertido en una magnífica realidad y la referencia es la CNTC.

\section{El Festival de Almagro y la CNTC}

El Festival y la Compañía Nacional de Teatro Clásico son dos instituciones de carácter público con unos mismos fines: el fomento y la exhibición del patrimonio teatral clásico español y extranjero. La relación del Festival y de la Compañía ha sido estrechísima desde que en 1986 se cre- 


\section{Teatro clásico e iniciativa pública}

ara esta última y todos los años, durante el mes de julio, la CNTC ha venido presentando habitualmente dos montajes en el Festival, siendo uno de ellos estreno absoluto en Almagro. La CNTC tuvo como primer espacio la Plaza de Santo Domingo y, a partir de 1994 (como ya hemos indicado), el Hospital de San Juan, que es, por otra parte, la sede de la Compañía Nacional durante el mes de julio como lo es el Teatro de la Comedia en Madrid durante los meses restantes. Es más, no debemos olvidar que la gestación de la Compañía debe mucho al Festival de Almagro y que no pocos acontecimientos que han afectado a la CNTC han tenido, el mes de septiembre primero y julio después, a Almagro como testigo.

$\mathrm{Si}$ el Festival no puede olvidar que nació en torno a unas Jornadas de estudio y que esas Jornadas en su devenir han sido decisivas para la mejor comprensión de nuestro Teatro Clásico, tampoco el Festival tendrá nunca perfecta explicación si no situamos en lugar privilegiado la treintena de espectáculos que, desde el calderoniano El médico de su honra hasta El Caballero de Olmedo, de Lope de Vega, y pasando por montajes inolvidables como los de El alcalde de Zalamea o El misántropo, han conseguido llenar los dos espacios utilizados por la CNTC permanentemente, y con unas puestas en escena que han tenido a los mejores profesionales españoles y a algunos de los mejores extranjeros como responsables de las mismas.

\section{Bibliografía selecta}

Ofrecemos, puesta al día, la Bibliografía que elaboramos para el número 16 de Cuadernos de Teatro Clásico (pp. 241-244).

DíEz Borque, José MARÍA (1994): “La fiesta sacramental calderoniana en 1992», Hacia Calderón. Décimo Coloquio Anglogermano. Nassau 1993, ed. H. Flasche, Stuttgart, Franz Steiner Verlag, Stuttgart, pp. 55-65.

- (1995): "Le théâtre espagnol revisité par le Festival d'Almagro et par la Compagnie Nationale de Théâtre Classique", Le patrimoine théâtral Européen revisité, ed. D. Levoy, París, Editions L'Harmattan, pp. 53-63.

DíEz Borque, José MARÍA y ANDRÉs PelÁez (2000): Calderón en escena: Siglo XX [Catálogo de la exposición], Comunidad de Madrid, Consejería de Cultura, Madrid.

El Corral de Comedias y la Villa de Almagro (2002): Toledo, Junta de Comunidades de Castilla La Mancha - Fundación de Cultura y Deportes de Castilla La Mancha.

FISCHER, SUSAN L. (2002a): "The warrant of womanhood: Rosaura on the Post-Modern Stage", Gestos, 33, pp. 49-70.

- (2002b): "Adolfo Marsillach Soriano (1982 2002)», Gestos, 33, pp. 181-183.

- (2001): “Del texto original al espectáculo actual: la fuerza de la intertextualidad en La vida es sueño", Hispanic Review, 69, pp. 209-237. 
- (2000a): "Así que pasen quince años: trayectorias escénicas de la Compañía Nacional de Teatro Clásico", Anales de Literatura española contemporánea, 25, 3, pp. 765-820.

- (2000b): "Fin de siècle Celestina on Stage: Whose Text Is It, Anyway?», Gestos, 29, pp. 56-75.

- (1999): “'Jolly Green Giants' or 'Palace Devils': Was Marsillach's Stage Translation of Tirso's Vergonzoso 'Vergonzoso' or 'Ingenioso'?», Romance Languages Annual, 10, pp. 570-579.

- (1997): «Fuente Ovejuna on the Rack: Interrogation of a Carnivalesque Theatre of Terror", Hispanic Review, 65, pp. 61-92.

- (1996): «Page Gazing through Subversive Staging: Calderón and L'Illusion Cinematographique», Self-Conscious Art: A Tribute to John W. Kronik, ed. Susan L. Fisher, Bucknell Review 39.2, pp. 102-127.

- (1993): "El médico de su honra, Semiotics and Performance: 'An Exercise in SelfExorcism'?", Gestos, 15, pp. 27-54.

- (1991): «El garrote más bien dado o El alcalde de Zalamea: Classical Theatre as It Ought to be Performed", Gestos, 12, pp. 33-51.

GaRCía LoRENZO, LuCIANO (2002): «Tirso en escena: de los años cuarenta a la Compañía Nacional de Teatro Clásico", Cuadernos de Teatro Clásico, 18, pp. 21-32.

- (2002): "Ciudad y Teatro: Almagro», en La Ciudad y la Cultura. Monográfico de Salamanca. Revista de Estudios, n 49, pp. 111-119.

- (1999): «Puesta en escena y recepción de Fuente Ovejuna (1940-1999)», "Que otro Lope no ha de haber..." Atti del Congresso Internazionale su Lope de Vega, Firenze, ed. Alinea, pp. 85-105.

- (1998a): "El burlador de Sevilla: procedimientos cómicos y puesta en escena», El ingenio cómico de Tirso de Molina, ed. de Ignacio Arellano, Blanca Oteiza y Miguel Zugasti, Pamplona, Universidad de Navarra, pp. 97-108.

- (1998b): "El teatro clásico en la escena contemporánea: Don Gil de las calzas verdes», Estudios de literatura española de los siglos XIX y XX. Homenaje a Juan María Díez de Taboada, Madrid, C.S.I.C., pp. 532-549.

- (1997): «Puesta en escena y recepción del teatro clásico español: Fuente Ovejuna de Lope de Vega", Hispanic Essays in Honor of Frank P. Casa, ed. by A. Robert Lauer and Henry W. Sullivan, New Cork, Peter Lang, pp. 112-121.

- (1995): "La recepción del teatro clásico español en la España última", La Comedia, ed. de Jean Canavaggio, Madrid, Casa de Velásquez, pp. 435-460.

- (1994): "La gran sultana de Miguel de Cervantes. Adaptación del texto y puesta en escena", Anales cervantinos, XXXII, pp. 117-136.

- (1993a): “Cervantes, Constantinopla y La gran sultana», Anales cervantinos, XXXI, pp. 201-213.

- (1993b): "La recepción del teatro clásico español: El desdén con el desdén de Agustín Moreto y La verdad sospechosa de Juan Ruiz de Alarcón", Revista de Literatura, LV, 110, pp. 557-572.

- (1987): «El Teatro clásico español en escena, 1976-1987», Insula, 492, pp. 21-22.

GARCía LORENZO, LUCIANO y MANUEL MUÑoz CARABANTES (2000): «El teatro de Calderón en la escena española (1939-1999)", Estado actual de los estudios calderonianos, ed. Luciano García Lorenzo, Kassel: Edition Reichenberger - Festival de Almagro, pp. 351-382.

García Lorenzo, Luciano, César Oliva, Ma Grazia Profeti y Arturo Ramoneda (enero-febrero 1997): “La puesta en escena del teatro clásico», Ínsula, 601-602. 


\section{Teatro clásico e iniciativa pública}

García LoREnZo, LuCiano y ANdRÉs PelÁez MARTín (1997): Festival Internacional de Teatro Clásico de Almagro. 20 años, Toledo, Festival de Almagro - Caja Castilla la Mancha.

HERNÁNDEZ ARAICO, SUSANA (1994): «Estreno de La gran sultana: teatro de lo otro, amor y humor", Cervantes, pp. 155-165.

Marsillach, Adolfo (1998): Tan lejos. Tan cerca: Mi vida, Madrid, Tusquets.

MuÑoz CaRABantes, M. (1992): Puesta en escena y recepción del teatro clásico y medieval en España (1939-1989), tesis doctoral presentada en la Universidad Complutense y dirigida por L. García Lorenzo.

Oliva, CÉSAR (1994): "Don Gil de las calzas verdes, hoy", En torno al teatro del Siglo de Oro, Almería, Instituto de Estudios Almerienses, pp. 247-250.

- (mayo 1989): «La crisis de Celestina o la humanización del teatro español. De Irene López de Heredia a Amparo Rivelles", Celestinesca, vol. 13, n 1, pp. 49-52.

OteizA, BlanCA (2002): «El lenguaje poético y dramático de Tirso. A propósito de El burlador de Sevilla y La celosa de sí misma», Cuadernos de Teatro Clásico, 18, pp. 37-55.

PEDRAZA Jiménez, F. B. (2003): «Tirso en escena», Ínsula, 681, pp. 29-30.

PELÁEZ, ANDRÉS (1996): "El teatro del Siglo de Oro ante la crítica y el público», En torno al Teatro del Siglo de Oro. Actas. Jornadas XII-XIII, Almería, Instituto de Estudios Almerienses, Diputación de Almería.

PÉREZ SiERRA, RAFAEL (1994): "Interpretación actual de la escena barroca», E. Bances Candamo y el teatro musical de su tiempo (1662-1704), eds. J.A. Gómez Rodríguez y B. Martínez, Oviedo, pp. 257-271.

RESINA RodRIgUes, MARÍA IDALINA (1994): "Fuente Ovejuna: as margens da memória», Revista da Faculdade de Letras, $\mathrm{n}^{\circ}$ 16/17-5a serie, pp. 7-18.

Romera CAstillo, José (1990): «El alcalde de Zalamea de Calderón y de Francisco Brines (dos signos de una serie semiótica)", Actas del III Congreso de Semiótica, Universidad de Granada, pp. 174-186.

SERRANO, ANTONIO (1992): «El teatro del Siglo de Oro entre los años 1985-1990", En torno al teatro del Siglo de Oro, Jornadas VII-VIII, Almería, Diputación - Instituto de Estudios Almerienses, pp. 183-198.

SMITH, DAWN L. (1993): «Calderón en Madrid y Londres: dos refundiciones de El alcalde de Zalamea", Vidas paralelas: el Teatro Español y el Teatro Isabelino: 1580-1680, Madrid, Támesis, pp. 125-135.

VIllaRINo, Edith MARTA (1996): “Una reciente puesta en escena de El burlador de Sevilla», Criticón, $\mathrm{n}^{\circ}$ 68, Presses Universitaires du Mirail, pp. 141-147.

\section{Apéndice}

\section{Publicaciones del Festival de Almagro*}

\section{Actas de las Jornadas de Teatro Clásico}

Almagro 1978. Jornadas de Teatro Clásico Español. Madrid, Ministerio de Cultura, 1979.

\footnotetext{
* Para las publicaciones de la CNTC, vid. Cuadernos de Teatro Clásico, 16, 2002.
} 
II Jornadas de Teatro Clásico Español. Almagro, 1979. Teatro Clásico Español: problemas de una lectura actual. Coord. Francisco RuIz RAmón, Madrid, Ministerio de Cultura, 1980.

III Jornadas de Teatro Clásico Español. Almagro, 1980. Ed. José MONLEÓN, Madrid, Ministerio de Cultura, 1981.

IV Jornadas de Teatro Clásico Español. Almagro, 1981. Ed. José MONLEÓN, Madrid, Ministerio de Cultura, 1981.

$V$ Jornadas de Teatro Clásico Español. El trabajo con los clásicos en el teatro contemporáneo. Almagro, 1982. Ed. Juan Antonio Hormigón, Madrid, Ministerio de Cultura, 1983, 2 vols.

El personaje dramático. Ponencias y debates de las VI Jornadas de Teatro Clásico Español (Almagro, 20 al 23 de septiembre de 1983). Ed. Luciano García LoRENZO, Madrid, Taurus, 1985.

El mito en el teatro clásico español. Ponencias y debates de las VII Jornadas de Teatro Clásico Español (Almagro, 25 al 27 de septiembre, 1984). Ed. Francisco RUIZ RAmón y César Oliva, Madrid, Taurus, 1988.

El mito de Don Juan. "Cuadernos de teatro clásico", n 2 (1988). (Jornadas de Almagro 1985). Ed. Luciano García Lorenzo, Madrid, Ministerio de Cultura, 1988.

Los géneros menores en el teatro español del Siglo de Oro (Jornadas de Almagro 1987). Ed. Luciano García LoREnZo, Madrid, Ministerio de Cultura, 1988.

Espacios teatrales del Barroco español. Calle-Iglesia-Palacio-Universidad. XIII Jornadas de Teatro Clásico. Almagro, 1990. Ed. José Ma DíEz BoRqUE, Kassel, Reichenberger, 1991.

XIV Jornadas de Teatro Clásico Español (Almagro, julio de 1991). Vidas paralelas. El teatro español y el teatro isabelino: 1580-1680. Ed. Anita K. STOLL, Londres, Tamesis Books, 1993.

El redescubrimiento de los clásicos. Actas de las XV Jornadas de teatro clásico. Almagro, julio de 1992. Ed. Felipe B. PedrazA JimÉnez, Universidad de Castilla La ManchaFestival de Almagro, 1993.

Los imperios orientales en el teatro del Siglo de Oro. Actas de las XVI Jornadas de teatro clásico. Almagro, julio de 1993. Ed. Felipe B. Pedraza Jiménez y Rafael GonZÁlez CAÑAL, Universidad de Castilla La Mancha - Festival de Almagro, 1994.

Los albores del teatro español. Actas de las XVII Jornadas de teatro clásico. Almagro, julio de 1994. Ed. Felipe B. Pedraza Jiménez y Rafael GonzÁlez Cañal, Universidad de Castilla La Mancha - Festival de Almagro, 1995.

Lope de Vega: comedia urbana y comedia palatina. Actas de las XVIII Jornadas de teatro clásico. Almagro, julio de 1995. Ed. Felipe B. Pedraza Jiménez y Rafael GonzÁlez CAÑAL, Universidad de Castilla La Mancha - Festival de Almagro, 1996.

La década de óro de la comedia española (1630-1640). Actas de las XIX Jornadas de teatro clásico (Almagro, julio de 1996). Ed. Felipe B. PEDRAZA Jiménez y Rafael GonzÁlez Cañal, Universidad de Castilla La Mancha - Festival de Almagro, 1997.

La década de oro de la comedia española (1630-1640). Actas de las XIX Jornadas de teatro clásico (Almagro, julio de 1996). Ed. Felipe B. PEDraZA JimÉnEz y Rafael GonzÁLEZ CAÑAL, Universidad de Castilla La Mancha - Festival de Almagro, 1997.

Las comedias de enredo. Actas de las XX Jornadas de teatro clásico (Almagro, julio de 1997). Ed. Felipe B. Pedraza Jiménez y Rafael GonzÁlez Cañal, Universidad de Castilla La Mancha - Festival de Almagro, 1998. 


\section{Teatro clásico e iniciativa pública}

El teatro en tiempos de Felipe II. Actas de las XXI Jornadas de teatro clásico (Almagro, julio de 1998). Ed. Felipe B. Pedraza Jiménez y Rafael GonzÁlez Cañal, Universidad de Castilla La Mancha - Festival de Almagro, 1999.

Francisco de Rojas Zorrilla, poeta dramático. Actas de las XXII Jornadas de teatro clásico (Almagro, julio de 1999). Ed. Felipe B. Pedraza JimÉnez, Rafael GonZÁlez CaÑal y Elena MARCELlo, Universidad de Castilla La Mancha - Festival de Almagro, 2000.

Calderón: sistema dramático y técnicas escénicas. Actas de las XXIII Jornadas de teatro clásico (Almagro, julio de 2000). Ed. Felipe B. PEdraza JimÉneZ, Rafael GonzÁlez CAÑAl y Elena MARCELlo, Universidad de Castilla La Mancha - Festival de Almagro, 2001.

La comedia villanesca y su escenificación. Actas de las XXIV Jornadas de teatro clásico (Almagro, julio de 2001). Ed. Felipe B. Pedraza Jiménez, Rafael González CAÑal y Elena MARCELLO, Universidad de Castilla La Mancha - Festival de Almagro, 2002.

Amor y erotismo en el teatro de Lope de Vega. Actas de las XXV Jornadas de teatro clásico (Almagro, julio de 2002). Ed. Felipe B. PEdRAZA JimÉnEz, Rafael GonZÁlez CAÑAL y Elena MARCELLO, Universidad de Castilla La Mancha - Festival de Almagro, 2003.

Tirso de capa y espada. Actas de las XXVI Jornadas de teatro clásico. Almagro, 8, 9 y 10 de julio de 2003. Edición cuidada por Felipe B. PEdRAZA JimÉnez, Rafael González CAÑAl y Elena MARCELlO, Universidad de Castilla La Mancha - Festival de Almagro, 2004.

\section{Otras publicaciones}

Festival Internacional de Teatro Clásico de Almagro. Ed. Luciano García Lorenzo y Andrés PelÁez Martín. Toledo, Caja Castilla La Mancha - Festival de Almagro, 1997.

La presencia de la mujer en el teatro barroco español. Ed. Mercedes DE LOS REYES PEÑA. Sevilla, Consejería de Cultura - Festival de Almagro, 1998.

Autoras y actrices en la historia del teatro español. Ed. Luciano GARCíA LORENZO. Universidad de Murcia - Festival de Almagro, 2000.

Calderón 2000. Guía calderoniana. Coordinado por Ignacio ARELlano y Juan Manuel EsCUDERO. Universidad de Navarra - Universidad de Castilla La Mancha - Festival de Almagro, 2000.

Estado actual de los estudios calderonianos. Ed. Luciano García LoREnZo. Kassel, Edition Reichenberger - Festival de Almagro, 2001.

Miguel Narros. Una vida para la escena. Ed. Luciano GarCía LoREnZo y Andrés PELÁEZ MARTín. Festival de Almagro, 2002.

\section{Versiones de textos clásicos}

Lope DE VEGA, (No son todos ruiseñores). Versión de Yolanda Pallín. Dirección de Eduardo Vasco. Ciudad Real, Naque Editorial - Festival de Almagro, 2000.

Calderón, ¿enamorado? Versión de José $\mathrm{M}^{\mathrm{a}}$ Ruano de la Haza. Dirección de José Maya. Ciudad Real, Naque Editorial - Festival de Almagro, 2000. 
Pedro CALDERón DE LA BARCA, El mayor hechizo, amor. Versión y dirección de Fernando Urdiales. Ciudad Real, Ñaque Editorial - Festival de Almagro, 2000.

Calderón, los clásicos y el flamenco. Textos escogidos por José $\mathrm{M}^{\mathrm{a}}$ Velázquez-Gaztelu. Coordinación de Norberto Dotor. Ciudad Real, Naque Editorial - Festival de Almagro, 2001.

Pedro Calderón de la Barca, El alcalde de Zalamea. Dirección de Sergi Belbel. Ciudad Real, Ñaue Editorial - Festival de Almagro, 2001.

William Shakespeare, Dos amigos de Verona. Versión y dirección de Carlos Marchena. Ciudad Real, Ñaque Editorial - Festival de Almagro, 2001.

William Shakespeare, Titus Andronicus. Versión y dirección de Fernando Urdiales. Ciudad Real, Naque Editorial - Festival de Almagro, 2001.

LoPe DE VEGA, La fuerza lastimosa. Versión de Yolanda Pallín. Dirección de Eduardo Vasco. Ciudad Real, Naque Editorial - Festival de Almagro, 2001. 